players on five occasions, twice at sea level, in order to create a baseline, and then again at $1000 \mathrm{~m}$ for acclimatisation and twice at $1600 \mathrm{~m}$. There was no effect of time, repeat assessment, or altitude on choice reaction time. The results of this study therefore suggest that moderate altitude has no significant determinable effect on choice reaction time in highly trained international competitive athletes. It is possible that altitude did result in an increase in choice reaction time, but that this was cancelled out by the effects of practice/repeat assessment. We think this an unlikely explanation, as there was no significant improvement between assessments 1 and 2 (the baseline), where the greatest practice effects would have been expected. As stated in the Introduction, clear deleterious effects on psychomotor speed can be observed above $4000 \mathrm{~m}$. However, it is still possible that subtle effects may occur at lower altitudes, but more sensitive measures would be needed to determine them.
We thank the players who represented Scotland in the 1995 World Cup for their participation. We also thank the Scottish Rugby Union Committee and the team management for their support. D M is also grateful to Professor Craig Sharp for help in reviewing the relevant literature. Finally, we would like to thank Norma Brearley for careful preparation of the manuscript.

1 Bahrke MS, Shukitt-Hale B. Effects of altitude on mood, behaviour and cognitive functioning. A review. Sports Med 1993;16:97-125.

2 Mackintosh JH, Thomas DJ, Olive JE, Chesner IM, Knight RJE. The effect of altitude on tests of reaction time and RJE. The effect of altitude on tests of reaction tim
alertness. Aviat Space Environ Med 1988;59:246-48.

3 Ledwith F. The effects of hypoxia on choice reaction time Ledwith F. The effects of hypoxia on choice reaction

and movement time. Ergonomics 1970;13:465-82.
Phillips LW, Griswold RL, Pace N. Cognitive changes at Phillips LW, Griswold RL, Pace N. Cogn
high altitude. Psychol Rep 1963;13:423-30

5 Kelman GR, Crow TJ, Bursill AE. Effect of mild hypoxia on mental performance assessed by a test of selective attention. Aerospace Medicine 1969;40:301-3.

6 Denison DM, Ledwith F, Poulton EC. Complex reaction times at simulated cabin altitudes of 5000 feet and 8000 feet. Aerospace Medicine 1966;37:1010-13.

7 Paul MA, Fraser WD. Performance during mild acutehypoxia. Aviat Space Environ Med 1994;65:891-89.

8 Frith CD, Leary J, Cahill C, Johnstone EC. Disabilities and circumstances of schizophrenic patients: a follow-up study. IV. Performance on psychological tests. Demographic and clinical correlates of the results of these tests. Br f Psychiatry 1991; 159(suppl):26-9.

\section{The shirt sign}

I wish to describe "The shirt sign"-a new clinical sign in steroid abuse. This is a clinical observation made during examination of the respiratory system of known anabolic steroid users. The sign refers to the mode of removal of the shirt and may be of two varieties.

The T-shirt. Instead of reaching behind the neck and pulling the T-shirt over the head in a haphazard and often undignified fashion, the steroid user crosses his arms in front of his body to grip the lower hem of his shirt and removes it in a graceful, flowing motion accompanied by progressive isometric contraction of the exposed upper body musculature.

The buttoned shirt. Patients usually loosen the top two buttons and then rapidly pull the shirt over the head. The steroid user slowly unbuttons from the top downwards while increasingly contracting latissimus dorsi and pectoralis major and, occasionally, deltoid muscles. This causes some difficulty in the undoing of the lower buttons as they disappear from view below the hypertrophied muscles. With the aforementioned muscles contracted, upper limb movement also becomes more restricted.

Auscultation of the respiratory system can be difficult as patients find it impossible to inhale fully and exhale smoothly while maintaining an impressive pose.

These observations are based on only two patients and I require validation in large scale case-control and prospective studies.

BRUCE THOMPSON

6 Connaught Park Lurgan

$N$ Ireland BT66 7AZ 